\title{
BIODIESEL PRODUCTION FROM MICROALGAE: INFLUENCE OF PRETREATMENT ON LIPID EXTRACTION
}

\author{
M. VEILLETTE ${ }^{1}$, A. GIROIR-FENDLER ${ }^{2}$, N. FAUCHEUX ${ }^{1} \&$ M. HEITZ ${ }^{1 *}$ \\ ${ }^{1}$ Department of Chemical Engineering and Biotechnological Engineering, \\ Engineering Faculty, Université de Sherbrooke, Canada. \\ ${ }^{2}$ Université de Lyon, Lyon F-69003, France. \\ *To whom all correspondance should be adressed.
}

\section{ABSTRACT}

By having the objective of reducing their global emissions of carbon dioxide $\left(\mathrm{CO}_{2}\right)$ and their petroleum dependency, many industrialized countries like European Union countries support the sustainable development and will increase, by 2020, the ratio of biofuel (bioethanol or biodiesel) blend with transportation fuel to $10 \%$ (v/v). However, this objective could deprive the world of arable lands needed to feed 320 to 460 million people. To replace conventional vegetable oils (for example, canola oil) to produce biodiesel, microalgae could be used as the bulk material, as their total lipid yield can be as high as $75 \%(\mathrm{w} / \mathrm{w})$. To produce biodiesel, the lipids must previously be extracted from the wet microalgae. This study showed that microalgae could be directly extracted without dewatering process with a yield of $29.0 \%(\mathrm{w} / \mathrm{w}$ ) by using boiling pretreatments (water phase). The yield obtained was slightly lower than the traditional extraction methods $(33.0 \% \mathrm{w} / \mathrm{w})$ implying the costly technique of freeze-drying. The results also showed that the chemical physicochemical pretreatment considered had no influence on the composition of the fatty acid methyl esters of the biodiesel produced with methyl palmitoleate as the major component with up to $28.0 \%$ (w/w).

Keywords: biodiesel, extraction, lipids, microalgae, transesterification

\section{INTRODUCTION}

Despite the energy saving due to the energy efficiency improvements, between 1973 and 2010, the world primary energy consumption increased by around $110 \%$ during this period with an energy equivalent consumption of 12 billion barrels of oil in 2010 [1]. During this period, the world population increased from around 3.9 to 6.9 billion [2,3], which might be an explanation for the increase in the energy consumption. Therefore, the energy consumption will probably increase as the world population could reach 9 billion people by 2050 [4].

In Canada and United States, over 70\% of the 2005 energy need is provided by fossil fuels (oil, natural gas and coal) [5]. Moreover, in the United States, most of the 2009 electricity was produced by non-renewable sources like coal (1750 billion $\mathrm{kWh}$ ) and natural gas (900 billion $\mathrm{kWh}$ ) [6].

Between 1980 and 2006, the world carbon dioxide $\left(\mathrm{CO}_{2}\right)$ emissions increased by $58 \%$, for a total emission of 29.2 billion of metric tons in 2006 [7]. Following the Copenhagen Climate Change Conference (2009), the governments intended to reduce their greenhouse gas (GHG) emissions to various levels [8]. Recently, several governments (United States and European Union countries) have formulated policies that state that transportation fuel must contain 10\% (v/v) of biofuels (mostly bioethanol and biodiesel) by 2020 [9]. Even if this objective is aimed at reducing the dependency on petroleum and $\mathrm{CO}_{2}$ emissions, this decision could lead to world hunger, land pollution and deforestation, as most of the biofuels are produced from raw oleaginous materials [10]. Moreover, the lack of land could create soil impoverishment problems [11].

Microalgae can be used to produce biofuels such as biodiesel and to reduce $\mathrm{CO}_{2}$ emissions at the same time. In fact, autotrophic microalgae are produced by photosynthesis, which consumes $\mathrm{CO}_{2}$ and water to form microalgae and oxygen. Some authors calculate that for each gram of microalgae formed, $1.83 \mathrm{~g}$ of $\mathrm{CO}_{2}$ is consumed [12]. Consequently, microalgae can help to reduce the $\mathrm{CO}_{2}$ emissions of combustion sources such as coal power plants [13] and cement plants [14].

(C) 2015 WIT Press, www.witpress.com

ISSN: 1743-7601 (paper format), ISSN: 1743-761X (online), http://journals.witpress.com

DOI: $10.2495 /$ SDP-V10-N3-385-398 
Microalgae are a rich source of oleaginous material, which can contain more than $75 \%$ (w/w) of lipids on a dry weight base [12]. The biodiesel produced through the transesterification of lipids can be blended from various ratios of petrodiesel ranging from $1 \%$ to $100 \%(\mathrm{v} / \mathrm{v})$ without prior engine modifications [15]. Blending 20\% (v/v) of biodiesel with regular petrodiesel allows to reduce general emissions like particular matters (10\%), carbon monoxide (11\%), hydrocarbon (21\%) [15], mercaptans (18\%) [16] and $\mathrm{CO}_{2}$ emissions (15.5\%) [17].

However, the main problem with biodiesel from microalgae is that the production costs for such biofuels are still high from 2.4 to 6.6 \$US/L [18]. To reduce the production costs, some studies have tried to find microalgae with a higher lipid yield [19], while other studies claim that physicochemical pretreatments microalgae biomass might increase the lipid extracted [20-22] or increase the fatty acid methyl ester (FAME) yield [23]. Some of these studies affirm that dry-freezing and microwave heating in water phase increase the yield of lipid extraction. The lipids must be extracted because water reduces the yield of biodiesel obtained [24].

The main goal of the present study is to compare extraction methods to determine which is most suitable to extract lipids from a blend of microalgae. The second purpose of this work is to determine if the extracted lipids from microalgae can be used for biodiesel production.

\section{MATERIALS AND METHODS}

\subsection{Feedstock and materials}

Frozen microalgae provided by NutrOcéan Canada, Inc. (Rimouski, Canada) was a blend of the following species: Nannochloropsis oculata, Isochrysis galbana and Pavlova lutheri. The elemental composition of the microalgae was determined using the wet weight, the dry weight (dw) (oven, $105^{\circ} \mathrm{C}$ ) and the calcinated weight (oven, $500^{\circ} \mathrm{C}$ ) of three samples as described elsewhere [25]. Table 1 presents the proximate analysis of the microalgae blend. Certified ACS grade solvents (methanol $\left(\mathrm{CH}_{3} \mathrm{OH}\right)$, isopropanol $\left(\mathrm{C}_{3} \mathrm{H}_{8} \mathrm{O}\right)$, chloroform $\left(\mathrm{CHCl}_{3}\right)$ and hexane $\left(\mathrm{C}_{6} \mathrm{H}_{14}\right)$ ) were supplied by Fisher Scientific, Inc. (Canada). Acetyl chloride $\left(\mathrm{CH}_{3} \mathrm{COCl}\right)$ (grade: puriss. p.a., $\geq 99 \%$ ) was provided by Fluka (Oakville, USA).

Lyophilization was performed using a Virtis specimen freeze drier (model 24DX24, Gardiner, New York, USA). Autoclaving, sonification and microwave heating were performed in a Thermo Scientific Napco model 9000D (Fisher Scientific, Inc., Canada), a mechanical ultrasonic model FS60H (Fisher Scientific, Inc., Canada) and a kitchen microwave (General Electric, Inc., Canada). Boiling was carried out using a hotplate (Fischer Scientific, Canada) with continuous magnetic stirring. Centrifugation was achieved using an Avanti Centrifuge model J-20XP (Beckmann Coulter, Inc., USA).

\subsection{Physicochemical pretreatments and extraction}

Lipids were extracted using a modified procedure used by Lee et al. [20]. Table 2 presents the extraction procedures of the microalgae lipids. In experiments 1-6 and 16-17, $1 \mathrm{~g}$ of lyophilized

Table 1: Proximate analysis of frozen microalgae.

\begin{tabular}{ll}
\hline & $\%(w / w)$ \\
\hline Moisture & $83.90 \pm 0.05$ \\
Solids & $16.10 \pm 0.05$ \\
Volatile matter & $12.80 \pm 0.30$ \\
Ash and fixed carbon & $3.30 \pm 0.25$ \\
\hline
\end{tabular}


microalgae was dissolved in $100 \mathrm{~mL}$ of water. In experiments 7-10 and 15, around $6.25 \mathrm{~g}$ of wet microalgae $(1 \mathrm{~g}(\mathrm{dw}))$ was blended with $95 \mathrm{~mL}$ of distilled water.

In experiments 1-4 and 7-10, the water/microalgae samples were submitted to the following pretreatments: no pretreatment, microwave $(5 \mathrm{~min}, 1000 \mathrm{~W}, 2475 \mathrm{MHz}$ ), osmotic shock (sodium chloride, $10 \% \mathrm{~m} / \mathrm{v}, 48 \mathrm{~h}$ ) and boiling (5 min, discontinuous stirring at $1200 \mathrm{rpm}$ ). In experiments 5 and 6, the samples were also submitted to the following pretreatments: autoclave $\left(1 \mathrm{~h}, 132^{\circ} \mathrm{C}\right.$, $286 \mathrm{kPa})$ and sonication $(100 \mathrm{~W}, 42 \mathrm{kHz})$. Then, the samples were cooled off and transferred into a separation funnel for extraction, blended with $100 \mathrm{~mL}$ chloroform-methanol $(1: 1, \mathrm{v} / \mathrm{v})$ and shaked vigorously during $1 \mathrm{~min}$.

In experiment 11, lyophilized microalgae were dissolved directly in $50 \mathrm{~mL}$ of chloroform and $50 \mathrm{~mL}$ of methanol was added. In experiments 12-14, lyophilized microalgae were dissolved in $100 \mathrm{~mL}$ of chloroform-methanol $(1: 1, \mathrm{v} / \mathrm{v})$ or $100 \mathrm{~mL}$ hexane and heated under a reflux for $5 \mathrm{~min}$. Then, the blends were cooled off. In experiments 12 and 13, the organic solvents/samples were transferred in a separation funnel, $100 \mathrm{~mL}$ of water was added and shacked for $1 \mathrm{~min}$. In experiment 14, the hexane/microalgae phase was filtered (Paper Whatman, \# 1).

In experiment 15, the samples were submitted to $5 \mathrm{~min}$ boiling pretreatment and cooled off. Then, $100 \mathrm{~mL}$ of hexane-isopropanol $(3: 2, \mathrm{v} / \mathrm{v})$ was added, the blend was transferred into a separation funnel and shacked for $1 \mathrm{~min}$.

For experiments 1-12 and 16 and 17, a microemulsion was observed in addition to aqueous and lipid phases. Only the bottom phase (lipid) was recovered in experiments 1-17 [20]. For experiments 16 and 17, centrifugation at room temperature was tested from 500 to $5000 \mathrm{rpm}$ during 1-3 min to mitigate the microemulsion. This test revealed that $2000 \mathrm{rpm}$ and $1 \mathrm{~min}$ were sufficient to mitigate the microemulsion and a more clear phases separation was observed (aqueous, semi-solid

Table 2: Lipids extraction experiments.

\begin{tabular}{llllll}
\hline Exp. & Initial state & First solvent & Pretreatment & Second solvents & Separation \\
\hline 1 & Lyophilized & W & No & M-C & Settling \\
2 & Lyophilized & W & Microwave & M-C & Settling \\
3 & Lyophilized & W & Boiling & M-C & Settling \\
4 & Lyophilized & W & Osmotic shock & M-C & Settling \\
5 & Lyophilized & W & Autoclave & M-C & Settling \\
6 & Lyophilized & W & Sonic bath & M-C & Settling \\
7 & Wet & W & No & M-C & Settling \\
8 & Wet & W & Microwave & M-C & Settling \\
9 & Wet & W & Boiling & M-C & Settling \\
10 & Wet & W & Osmotic shock & M-C & Settling \\
11 & Lyophilized & C & No & M-W & Settling \\
12 & Lyophilized & C-M & Reflux & W & Settling \\
13 & Lyophilized & H & Reflux & W & Settling \\
14 & Lyophilized & H & Reflux & & Filtration \\
15 & Wet & W & Boiling & I-H & Settling \\
16 & Lyophilized & W & Boiling & C-M & Settling and centrifugation \\
17 & Lyophilized & W & Boiling & H-M & Settling and centrifugation \\
\hline
\end{tabular}

*W, water ; M, methanol; C, chloroform; I, isopropanol; H, hexane. 
and chloroform). Ultrasound bath ( $100 \mathrm{~W}, 42 \mathrm{kHz}$ ) was also tested, but centrifugation was a lot more effective.

For all experiments, the solvents were evaporated at $60^{\circ} \mathrm{C}$ under a vacuum. Crude lipids were weighed using an electronic scale. The yield of lipids extraction was an average of three replicates. The lipid yield was expressed as a function of the initial microalgae weight.

\subsection{Lipids transesterification and biodiesel recovery}

Extracted crude lipids (0.16-0.29 g) were transesterified according to Lepage and Roy [26] modified procedure. This procedure was chosen because it produced a higher FAME yield than other catalysts such as hydrochloric acid or sulphuric acid (3\%, v/v) for transmethylation of microalgae lipids [27]. Crude lipids were blended with $4.02 \mathrm{~mL}$ of freshly made methanol-acetyl chloride (100:5, v/v) and heated in a water bath to around $100^{\circ} \mathrm{C}$ (with agitation at $1200 \mathrm{rpm}$ ) for $1 \mathrm{~h}$ under a reflux. The blend was cooled off at room temperature and the methanol was evaporated at $60^{\circ} \mathrm{C}$ under vacuum. Then, the crude biodiesel was recovered with $20 \mathrm{~mL}$ of pure hexane, which created a two-phase system as the glycerol and the chlorophyll was insoluble in hexane phase [28]. The top layer was recovered and filtered through a silica filter paper to remove residual water (Paper Whatman, P.S. \# 1). Hexane was evaporated at $60^{\circ} \mathrm{C}$ under a vacuum and then in an oven at $60^{\circ} \mathrm{C}$ for $15 \mathrm{~min}$ to eliminate the residual solvents. The lipid yield of different treatments was compared using one-way ANOVA and Tukey tests with $P<0.05$.

\subsection{Analytical methods}

The FAME qualitative composition of biodiesel was determined using a Varian-3800 gas chromatograph equipped with a mass spectrometer (Varian, Inc., Canada). A standard of 37 FAMEs (Supelco, 18919-1AMP) was used to identify the different methyl esters. One microlitre of hexane-biodiesel was injected in a DB-Wax polyethylene glycol capillary column $(30 \mathrm{~m} \times 0.25 \mathrm{~mm}$ ID, $0.25-\mathrm{mm}$ film thickness) with a split ratio of 20:1. Chromatographic analysis was made according to a similar procedure of Halim et al. [28]. Helium, used as the carrier gas, was set to a flow rate of $1.5 \mathrm{~mL} / \mathrm{min}$ and the injector temperature was constant at $150^{\circ} \mathrm{C}$. The oven was heated from 140 to $240^{\circ} \mathrm{C}$ at $5^{\circ} \mathrm{C} /$ min and maintained at $240^{\circ} \mathrm{C}$ for $5 \mathrm{~min}$. FAME quantitative composition was determined using a flame ionization detector (FID) and with Supelco standards for quantification (GLC-10, GLC-50, GLC-80, 18913-1AMP). Pure hydrogen gas was fed to the FID at a temperature of $240^{\circ} \mathrm{C}$ and nitrogen was used as a make-up gas at a flow rate of $30 \mathrm{~mL} / \mathrm{min}$. The FAME qualitative composition of biodiesel was an average of three replicates.

\section{RESULTS AND DISCUSSION}

\subsection{Extraction of lipids}

\subsubsection{Effect of pretreatment}

Figure 1 presents the lipid extraction yields for lyophilized microalgae for the different pretreaments. As seen in Fig. 1, the average lipid yield varied from $16.4 \%$ to $29.0 \%$ (dw). The water boiling pretreatment gave the higher average lipid $(29.0 \%(\mathrm{dw}))$ yield followed by osmotic shock $(28.7 \%$ $(\mathrm{dw}))$ and microwave $(28.0 \%(\mathrm{dw}))$.

Results show that the microalgae blend (N. oculata, I. galbana and P. lutheri) might be appropriate to produce biodiesel as their lipid yield is relatively high. The lipid yield obtained in the present study was similar to the results obtained by Lee et al. [21] with the species Botrycoccus braunii 
using a slightly different extraction process. As $B$. braunii could have a potential lipid content up to $75 \%(\mathrm{dw})$ (in specific culture conditions) [12], the blend of microalgae used in the present study demonstrated its potential for biodiesel production, as B. braunii has a growth rate 10 times slower than I. galbana, one of the microalgae used in the present study [29].

Even if a higher lipid yield was obtained with microwave pretreatment compared with no pretreatment, boiling and osmotic shock pretreatments gave statistically the same yield with $28.7 \%$ (dw) and $28.0 \%$ (dw), respectively. In their study, Lee et al. [20] tested some extraction methods including no pretreatment, microwave ( $5 \mathrm{~min}$ ), autoclave, bead-beating, osmotic shock and sonication. They concluded that microwave is the best pretreatment method for increasing the lipid yield $(29.0 \%(\mathrm{dw}))$ for the microalgae Botrycoccus sp. However, in the same study with another species (Chlorella vulgaris), microwave had a less significant effect $(9.8 \%(\mathrm{dw}))$. Consequently, the temperature induced by microwave heating could be more effective to disrupt the cells or to increase the solubility of lipids in water than the microwave itself. These data are important because microwave heating systems could be more expensive than conventional heating. This could also explain why sonic bath pretreatments gave a lower lipid yield $(16.4 \%(\mathrm{dw}))$.

The fact that the autoclave gave a lower lipid yield than others pretreatments probably means that the higher temperature and pressure could lead to the degradation (hydrolysis) of some lipids (19.4\% $(\mathrm{dw})$ ). Some other studies observed that thermal pretreatment using an autoclave from 75 to $120^{\circ} \mathrm{C}$ (unknown pressure) during 10 min could increase the FAME yield from $0.4 \%$ to $98.3 \%$ (dw) (compared with chloroform-methanol extraction) using hexane as extraction solvent [23]. No such observations were made in the present study.

The extraction procedure used in the present study was effective to destruct the cell wall of the microalgae, as a microemulsion was obtained. To our best knowledge, this phenomenon has never been reported. However, Cooney et al. [27] mentioned that 'shear stress and aggressive mixing' could form microemulsions in water phase. The authors also reported the formation of a microemulsion following the application of microwave to a water-microalgae system that would interfere with the natural settling process of water-methanol-chloroform extraction. In the present study, most of the water-methanol-chloroform extractions formed surprisingly stable microemulsions even after $10 \mathrm{~h}$ of settling. Therefore, a centrifugation supplementary step was added to Lee et al. [20] method to mitigate the microemulsion.

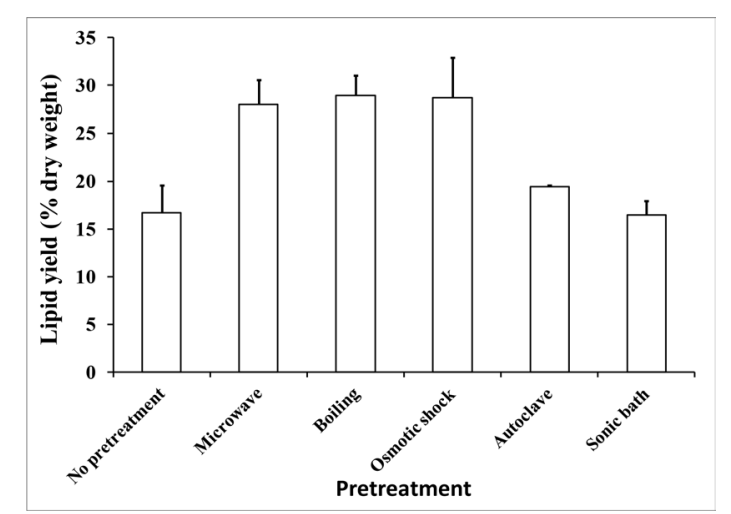

Figure 1: Lipid yield as a function of the pretreatment for lyophilized microalgae. 


\subsubsection{Effect of lyophilization}

Figure 2 presents the lipid yield obtained from different pretreatments for lyophilized and wet microalgae. As seen in Fig. 2, the yields obtained from the different pretreatments from lyophilized and wet microalgae varied from $16.7 \%$ to $28.9 \%$ and from $17 \%$ to $30.8 \%$ (dw), respectively.

No significant difference in lipids yield was observed for lyophilized and wet microalgae. Using lyophilized microalgae appear useless in the present study because freeze-drying (or any drying process) increases the extraction costs. Other studies observed an improvement of extraction when the cells were dry-freezed [21]. This could probably mean that $B$. braunii microalgae used by Lee et al. [21] has a harder cell wall to disrupt than the blend of microalgae used in the present study.

For wet microalgae, no significant difference in lipid yield was either observed between microwave, boiling and osmotic shock with value ranging from $26.1 \%$ to $30.9 \%$ (dw).

\subsubsection{Effects of solvents and heat}

Figure 3 presents the yield of lipid yield as a function of the solvent sequence (chloroform-methanolwater) for lyophilized microalgae. This figure shows that blending microalgae with chloroform instead of water gave a statistically higher lipid yield of 32.0 versus $16.7 \%$ (dw).

Data from Fig. 3 suggest that lyophilization could be more useful to favour the contact of lipids with non-polar solvents (chloroform) than for disrupting the microalgae cell walls because a higher lipid yield was obtained when the lyophilized microalgae were directly in contact with chloroform $(32.0 \%(\mathrm{dw}))$ compared with water $(16.7 \%(\mathrm{dw}))$. This result is similar to others studies on the effect of the chloroform-methanol-water sequence on lipid extraction and FAME yields [27,32]. For example, using a heterotrophic microalgae (strain ACEM 6063), Lewis et al. [32] obtained an increase in the FAME yield from $26 \%$ to $33 \%$ (dw) by changing the order of solvent (chloroformmethanol-water). Blending microalgae directly in chloroform requires, on the other hand, lyophilization which might increase the harvesting costs of the microalgae cells.

Figure 4 presents the lipid yield for chloroform-methanol and hexane reflux extracted with water. As seen in Fig. 4, the lipid yield obtained was statistically higher (33.0\% (dw)) for chloroformmethanol than for hexane $(23.2 \%(\mathrm{dw}))$ extracted with water, even if the amount of chloroform was twice lower than the amount of hexane. Comparing hexane-isopropanol $(3: 2, \mathrm{v} / \mathrm{v})$ and chloroformmethanol $(2: 1, \mathrm{v} / \mathrm{v})$ to extract the lipids from the wet microalgae $B$. braunii, Lee et al. [21] obtained a lipid yield of $20 \%$ and $29 \%$ (dw), respectively. This phenomenon can be explained by the fact that chloroform is a more polar solvent than hexane, which allowed chloroform to extract polar lipids

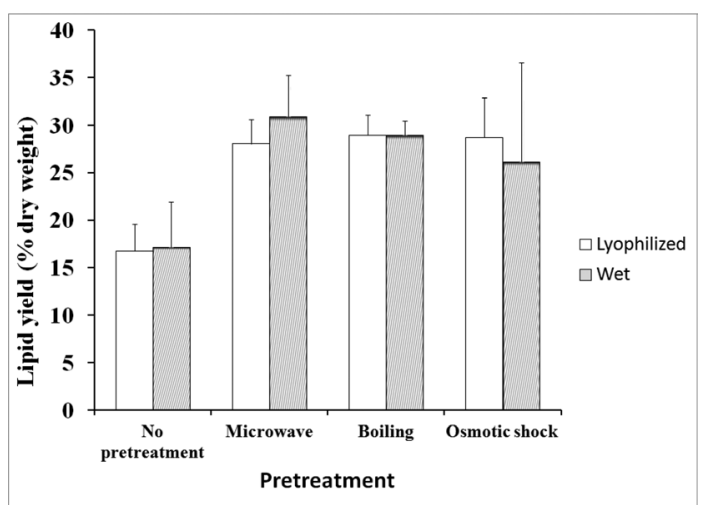

Figure 2: Lipid yield as a function of the pretreatment for lyophilized and wet microalgae. 


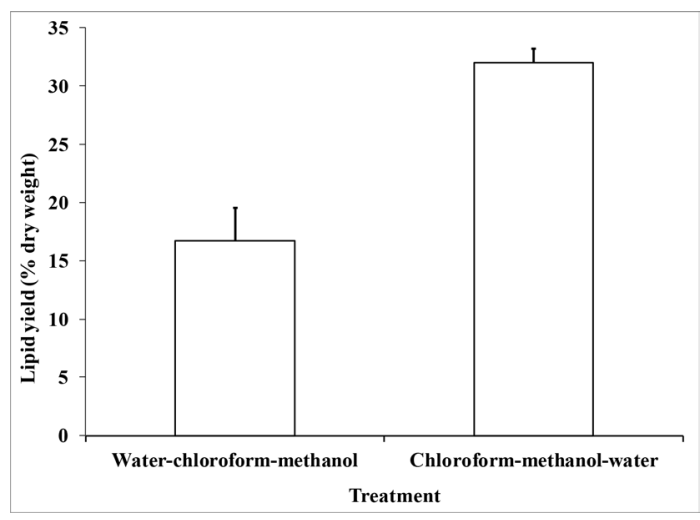

Figure 3: Lipid yield as a function of the extraction for sequence of extraction of chloroformmethanol-water of lyophilized microalgae.

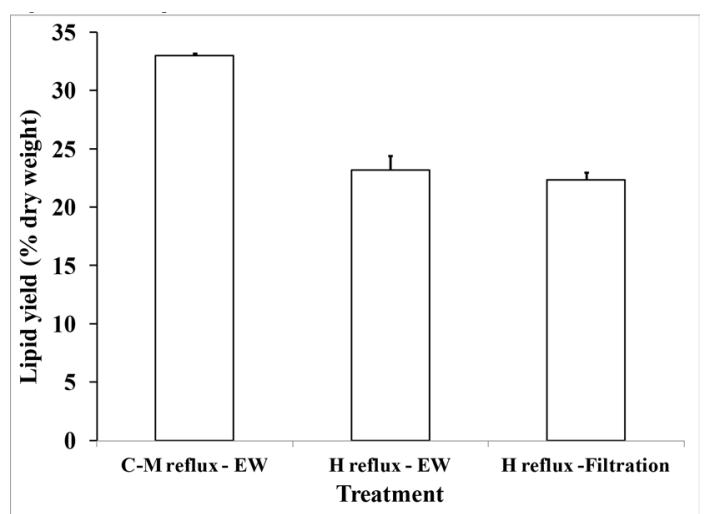

Figure 4: Lipid yield as a function of the extraction for lyophilized microalgae lipids extraction by reflux in chloroform-methanol and hexane (C: chloroform; $\mathrm{M}$ : methanol; H: hexane; EW: extracted with water).

such as glycolipids and phospholipids. Other studies have shown that hexane could extract a lower lipid yield (up to twice lower at $8 \% \mathrm{dw}$ ) than other more polar solvents (ethanol, octanol, 1,8-diazabicyclo-[5.4.0]-undec-7-ene), but the FAME yield obtained from lipids extracted with hexane could be more than 4.5 times higher at $2.7 \%$ (g biodiesel/g dry) [33]. Some microalgae can contain up to 93\% (g/g lipids) of glyco- and phospho- lipids and 7\% (g/g lipids) of simple lipids (free fatty acids, triglycerides, etc.) [34]. Even if chloroform-methanol was more effective than hexane to extract lipid, the latter is less toxic [35]. The addition of an alcohol to the hexane phase would probably have increased the lipid yield [28] but would have complicated the wastewater treatment.

The lipid yield obtained with chloroform-methanol reflux followed by an extraction with water (Fig. 4) was not statistically higher than the lipid yield using an extraction with chloroform-methanol-water without reflux (Fig. 3), which indicates that increasing temperature does not help to extract more lipids.

However, the fact that some pretreatment extraction tests (microwave and osmotic shock) reached higher values $(>36 \%(\mathrm{dw}))$ than chloroform-methanol reflux extracted with water would probably 
mean that the method could still be optimized. A microemulsion was not observed for the chloroformmethanol reflux, which probably means that polar lipids such as phospholipids [36] were not recovered using chloroform-methanol reflux extracted with water. This explains why hexane extracted less lipids as discussed previously. Therefore, for microalgae with a high phospholipids yield, the microemulsion could be reduced with sodium sulphate, centrifugation or sonication [37].

Figure 5 presents the influence of different solvents on the lipids yield for wet microalgae. As seen in Fig. 5, the yields of extraction crude lipids varied from $24.3 \%$ to $29.0 \%$ (dw).

Even if water-hexane-isopropanol gave a relatively high lipid yield of extraction (24.3\% (dw)) compared with chloroform-methanol-water extraction (29\% (dw)), this solvent mixture should be avoided because of the difficulty in identifying the different phases after settling. The polarity of the lipids contained in the microalgae used in the present study could favour the mixing of isopropanol and water into the hexane phase. Thus, even after removing the solvent at $60^{\circ} \mathrm{C}$ by vacuum evaporation, residual water and isopropanol remained with the organic phase. Moreover, isopropanol has a higher normal boiling point than methanol $\left(82^{\circ} \mathrm{C}\right.$ versus $\left.65^{\circ} \mathrm{C}\right)$, which means that more energy would be required for the extraction. Water also has to be removed by drying over sodium sulphate. Nagle and Lemke [38] used a supplementary step of chloroform-methanol-water extraction to isolate lipids from hexane extraction.

\subsubsection{Effect of centrifugation}

Figure 6 presents the influence of centrifugation on the lipid yield for boiled lyophilized microalgae extracted with water-chloroform-methanol $(2: 1: 1, \mathrm{v} / \mathrm{v})$ and water-hexane-methanol $(5: 3: 2, \mathrm{v} / \mathrm{v})$. As seen in Figure 6, the lipid yield obtained varied from 17.8 to $35.0 \%$ (dw). The centrifugation of the chloroform emulsion increased the lipid yield from 29.0 to $35.0 \%$ (dw). Using a water-hexanemethanol extraction lower the lipid yield with $17.8 \%$ (dw) even if a centrifugation was used to break the microemulsion.

Figure 6 presents the influence of centrifugation on the lipid yield of boiled lyophilized microalgae.

As seen in Fig. 6, the lipid yield obtained varied from $17.8 \%$ to $35.0 \%$ (dw). The centrifugation caused an increase in the lipid yield from $29.0 \%$ to $35.0 \%$ (dw). Using a water-methanol-hexane yields the lower yield with $17.8 \%$ (dw) even by using a centrifugation to break the microemulsion.

For boiled lyophilized microalgae in water followed by a chloroform-methanol extraction, adding a centrifugation increased significantly the lipids yield $(35.0 \%(\mathrm{dw}))$ compared with no centrifugation

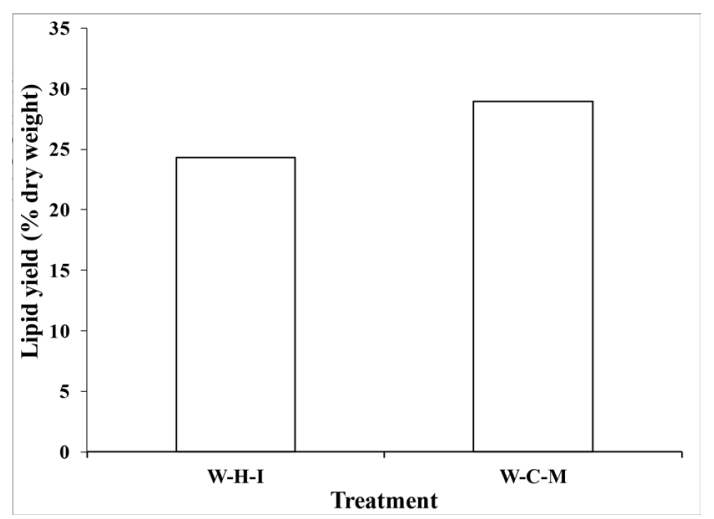

Figure 5: Influence of solvents composition for wet microalgae boiling (W: water; I: isopropanol; C: chloroform; M: methanol). 


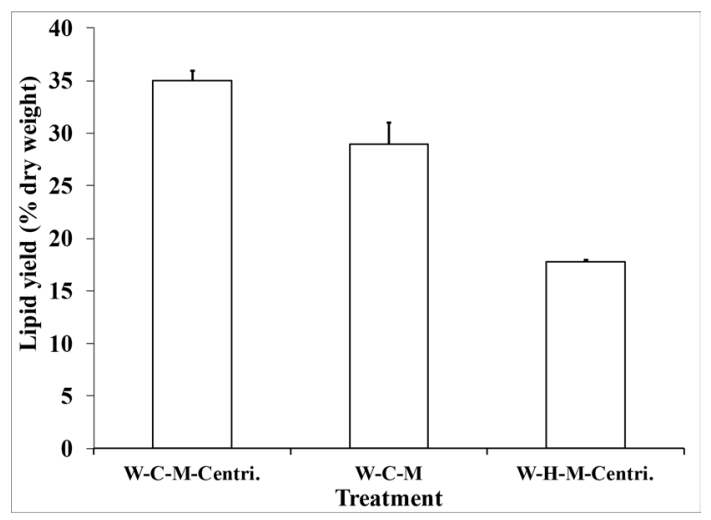

Figure 6: Influence of centrifugation on the lipid yield of boiled lyophilized microalgae (W: water; C: chloroform; M: methanol; Cent: centrifugation).

$(29 \%(\mathrm{dw}))$ and reduced the standard deviation of the lipids yield from $4 \%$ to $1.8 \%$ (dw). Consequently, the centrifugation is seen as essential to maximize the lipid recovery when microalgae are dissolved in water. Some other method procedures were used to extract lipids from a water phase, which includes a higher settling time of $18 \mathrm{~h}$ with occasional shaking [32] or/and washing with more extracting solvents [21]. Centrifugation was used in some studies (on a smaller scale) to extract lipids from fresh microalgae using different solvents [22,33,39]. For example, using a microalgae (B. braunii) concentration of $0.8 \mathrm{~g}(\mathrm{dw}) / \mathrm{L}$, Samorì et al. [33] used centrifugation to separate the different extraction phases.

For boiled lyophilized microalgae in water extracted with hexane-methanol, no lipid yield was obtained without centrifugation (data not shown), which could mean that the components at the origin of the microemulsion have probably more affinity for hexane than chloroform because the latter is more polar than hexane. Moreover, the microemulsion issued from hexane extraction was more difficult to mitigate than the microemulsion from chloroform extraction, as the centrifugation speed used was higher (3000 vs. 2000 rpm).

\subsection{FAME composition}

Figure 7 presents the FAME mass composition of the biodiesel produced as a function of the physicochemical pretreatment. The FAME mass composition is relatively constant whatever may be the physicochemical pretreatment. The main components were $(\% \mathrm{w} / \mathrm{w})$ : methyl palmitoleate $(25.7-$ 27.7), methyl eicosapentaenoate (20.0-21.9), methyl palmitate (12.5-14.5) and methyl docosahexanoate $(9.1-12.0)$.

The results demonstrated that the different pretreatments did not interfere with the chemical composition of the biodiesel produced. Based on our actual knowledge, even if studies have been conducted on the influence of pretreatments on lipid yield determined by gravimetric methods [20, 21], none of the studies have tested if the biodiesel composition was affected by the physicochemical pretreatments. On the other hand, other studies have shown that the nature of solvent did not statistically influence the composition of the different FAMEs of the biodiesel [33].

The fact that methyl palmitoleate is a major compound $(25.7-27.7 \% \mathrm{w} / \mathrm{w})$ could have some advantages. In fact, the cetane number of methyl palmitoleate (51) is higher than the minimal cetane 


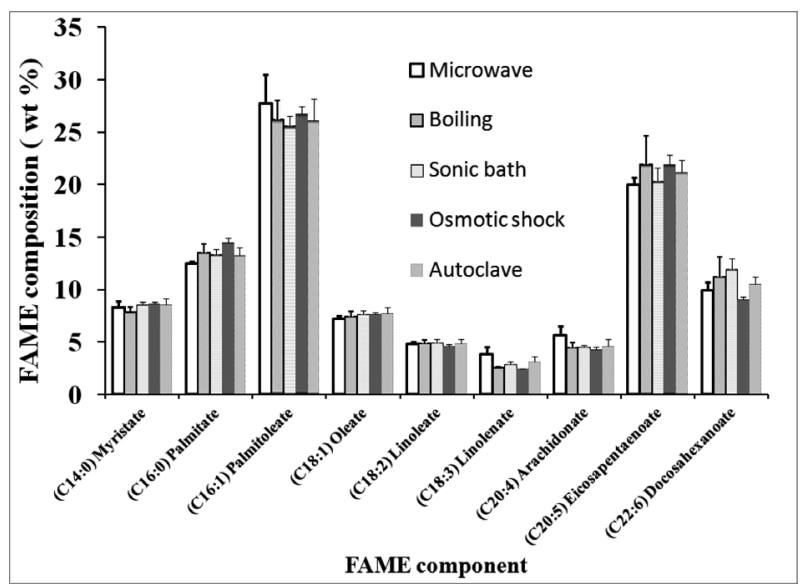

Figure 7: Biodiesel mass composition as a function of the extraction method.

number required by the ASTM for petrodiesel [40]. However, around 38\% (w/w) of the compounds of the biodiesel produced have more than three double bounds. A high content of polyunsaturated compounds (up to 56\% (w/w)) have also been reported from other studies [24,32]. A higher polyunsaturated composition of the biodiesel can lead to potential oxidation stability problems and a lower cetane number. For increasing the cetane number, it was proposed to hydrogenate the microalgae lipids to reduce the content of polyunsaturated compounds [12,41]. To overcome the oxidation stability problems, antioxidants (stabilizers) can also be added to increase the life storage of the microalgae biodiesel $[24,41]$.

\section{CONCLUSION}

The goal of this study was to compare several physicochemical pretreatments to extract the crude lipids contained in a mixed species of microalgae ( $N$. oculata, I. galbana and P. lutheri) and transform them into biodiesel. The maximum average lipid yield obtained was $35.0 \%$ (dw) from boiling pretreatment of lyophilized microalgae with chloroform-methanol solvent extraction and centrifugation separation. Moreover, centrifugation appeared indispensable for lipid extraction to obtain more reproducible results.

As the lipid yield is high $(35.0 \%(\mathrm{dw}))$, the blend of microalgae is interesting for biodiesel production. Despite the different pretreatments, the mass composition of the biodiesel obtained remains constant with methyl palmitoleate as the main constituent with up to $28 \%$ (w/w). However, $38 \%$ (w/w) of the FAME content was composed of polyunsaturated fatty acids (more than three doubles bonds), which can have a negative impact on the oxidation stability. Oxidation stability problem can be mitigated by adding antioxidants.

\section{ACKNOWLEDGEMENTS}

The authors are grateful to le Fond Québécois de la Recherche sur la Nature et les Technologies (FQRNT) for the grant to Michèle Heitz and Nathalie Faucheux for the research program in partnership contributing to the reduction of GHGs. Marc Veillette also wants to express his gratitude to FQRNT for the doctorate scholarship. Thanks also have to be expressed to the biology department of Université de Sherbrooke for the use of the lyophilization apparatus. 


\section{REFERENCES}

[1] BP, Statistical Review of World energy: Full Report 2011, available at http://www.bp.com, 2012.

[2] United Nations, World Population Prospects: The 2006 Revision, available at http://www. un.org/esa/population/publications/wpp2006/WPP2006_Highlights_rev.pdf, 2006.

[3] Population Division of the Department of Economic and Social Affairs of the United Nations Secretariat, Online database population, available at http://esa.un.org/wpp/unpp/p2k0data.asp, 2012.

[4] United Nations Department of Economic and Social Affairs, World population prospects: the 2008 revision. Population Newsletter, 87, pp. 1-20, 2009.

[5] International Energy Agency, Worldwide Trends in Energy Use and Efficiency, available at http://www.env-edu.gr/Documents/Worldwide\%20Trends\%20in\%20Energy $\% 20$ Use $\% 20$ and\%20Efficiency.pdf, 2008.

[6] U.S. Energy Information Administration, Annual Energy Outlook - 2011, available at http:// www.eia.doe.gov/forecasts/aeo/pdf/0383(2011).pdf, 2011.

[7] Energy Information Administration, International Carbon Dioxide Emissions and Carbon Intensity, U.S. Energy Information Administration, available at http://www.eia.doe.gov/emeu/ international/carbondioxide.html, 2008.

[8] Conseil économique pour le développement durable, Après Copenhag: Des engagements à géométrie variables, République Française, available at http://www.developpement-durable. gouv.fr/IMG/pdf/013b.pdf, 2010.

[9] Bindraban, P.S., Bulte, E.H. \& Conijn, S.G., Can large-scale biofuels production be sustainable by 2020? Agricultural Systems, 101, pp. 197-199, 2009. doi: http://dx.doi.org/10.1016/j. agsy.2009.06.005

[10] Goldemberg, J. \& Guardabassi, P., Are biofuels a feasible option? Energy Policy, 37(1), pp. 10-14, 2009. doi: http://dx.doi.org/10.1016/j.enpol.2008.08.031

[11] Bordet, J., Michez, J. \& Gilot, A., Mise en oeuvre du plan biocarburant au regard de la protection de la ressource en eau, Ministère de l'agriculture, de l'alimentation, de la pêche, de la ruralité et de l'aménagement du territoire, available at http://agriculture.gouv.fr/IMG/pdf/ plan_biocarburants.pdf, 2006.

[12] Chisti, Y., Biodiesel from microalgae. Biotechnology Advances, 25(3), pp. 294-306, 2007. doi: http://dx.doi.org/10.1016/j.biotechadv.2007.02.001

[13] de Morais, M.G. \& Costa, J.A.V., Isolation and selection of microalgae from coal fired thermoelectric power plant for biofixation of carbon dioxide. Energy Conversion and Management, 48(7), pp. 2169-2173, 2007. doi: http://dx.doi.org/10.1016/j.enconman.2006.12.011

[14] Borkenstein, C.G., Knoblechner, J., Frühwirth, H. \& Schagerl, M., Cultivation of Chlorella emersonii with flue gas derived from a cement plant. Journal of Applied Phycology, 23(1), pp. 131-135, 2011. doi: http://dx.doi.org/10.1007/s10811-010-9551-5

[15] United States Environmental Protection Agency, A comprehensive analysis of biodiesel impacts on exhaust emissions, available at www.biodiesel.org/.../20021001_gen-323.pdf, 2002.

[16] Machado Corrêa, S. \& Arbilla, G., Carbonyl emissions in diesel and biodiesel exhaust. Atmospheric Environment, 42, pp. 769-775, 2008. doi: http://dx.doi.org/10.1016/j.atmosenv.2007.09.073

[17] Sheehan, J., Combreco, V., Duffield, J., Graboski, M. \& Shapouri, H., An overview of biodiesel and petroleum diesel life cycles, National Renewable Energy Laboratory, available at http:// www.nrel.gov/docs/legosti/fy98/24772.pdf, 1998.

[18] Singh, J. \& Gu, S., Commercialization potential of microalgae for biofuels production. Renewable and Sustainable Energy Reviews, 14(9), pp. 2596-2610, 2010. doi: http://dx.doi. org/10.1016/j.rser.2010.06.014 
[19] Sheehan, J., Dunahay, T., Benemann, J. \& Roessler, P., A look back at the U.S. Department of Energy's aquatic species program - biodiesel from algae, U.S. Department of Energy's Office of Fuels Development, available at http://www.nrel.gov/docs/legosti/fy98/24190.pdf, 1998.

[20] Lee, J., Yoo, C., Jun, S., Ahn, C. \& Oh, H., Comparison of several methods for effective lipid extraction from microalgae. Bioresource Technology, 101, pp. 575-577, 2010. doi: http:// dx.doi.org/10.1016/j.biortech.2009.03.058

[21] Lee, S., Yoon, B. \& Oh, H., Rapid method for the determination of lipid from the green alga Botryococcus braunii. Biotechnology Techniques, 12(7), pp. 553-556, 1998. doi: http://dx.doi. org/10.1023/a:1008811716448

[22] Pernet, F. \& Tremblay, R., Lipids, 38(11), pp. 1191-1195, 2003.

[23] Kita, K., Okada, S., Sekino, H., Imou, K., Yokoyama, S. \& Amano, T., Thermal pre-treatment of wet microalgae harvest for efficient hydrocarbon recovery. Applied Energy, 87(7), pp. 24202423, 2010. doi: http://dx.doi.org/10.1016/j.apenergy.2009.11.036

[24] Johnson, M.B. \& Wen, Z., Production of biodiesel fuel from the microalga Schizochytrium limacinum by direct transesterification of algal biomass. Energy Fuels, 23, pp. 5179-5183, 2009. doi: http://dx.doi.org/10.1021/ef900704h

[25] Veillette, M., Viens, P., Avalos Ramirez, A., Brzezinski, R. \& Heitz, M., Effect of ammonium concentration on microbial population and performance of a biofilter treating air polluted with methane. Chemical Engineering Journal, 171(3), pp. 1114-1123, 2011. doi: http://dx.doi. org/10.1016/j.cej.2011.05.008

[26] Lepage, G. \& Roy, C.C., Improved recovery of fatty acid through direct transesterification without prior extraction or purification. Journal of Lipid Research, 25(12), pp. 1391-1396, 1984.

[27] Cooney, M., Young, G. \& Nagle, N., Extraction of bio-oils from microalgae. Separation \& Purification Reviews, 38, pp. 291-325, 2009.

[28] Halim, R., Gladman, B., Danquah, M.K. \& Webley, P.A., Oil extraction from microalgae for biodiesel production. Bioresource Technology, 102(1), pp. 178-185, 2010. doi: http://dx.doi. org/10.1016/j.biortech.2010.06.136

[29] Cadoret, J. \& Bernard, O., La production de biocarburant lipidique avec des microalgues: promesses et défis. Journal de la Société de Biologie, 202(3), pp. 201-211, 2008. doi: http:// dx.doi.org/10.1051/jbio:2008022

[30] Mahesar, S.A., Sherazi, S.T.H., Abro, K., Kandhro, A., Bhanger, M.I., van de Voort, F.R. \& Sedman, J., Application of microwave heating for the fast extraction of fat content from the poultry feeds. Talanta, 75(5), pp. 1240-1244, 2008. doi: http://dx.doi.org/10.1016/j.talanta.2008.01.042

[31] Virot, M., Tomao, V., Ginies, C., Visinoni, F. \& Chemat, F., Microwave-integrated extraction of total fats and oils. Journal of Chromatography A, 1196-1197, pp. 57-64, 2008. doi: http:// dx.doi.org/10.1016/j.chroma.2008.05.023

[32] Lewis, T., Nichols, P.D. \& McMeekina, T.A., Evaluation of extraction methods for recovery of fatty acids from lipid-producing microheterotrophs. Journal of Microbiological Methods, $\mathbf{4 2}$, pp. 107-116, 2000. doi: http://dx.doi.org/10.1016/s0167-7012(00)00217-7

[33] Samorì, C., Torri, C., Samorì, G., Fabbri, D., Galletti, P., Guerrini, F., Pistocchi, R. \& Tagliavini, E., Extraction of hydrocarbons from microalga Botryococcus braunii with switchable solvents. Bioresource Technology, 101(9), pp. 3274-3279, 2010. doi: http://dx.doi.org/10.1016/j. biortech.2009.12.068 
[34] Williams, P.J. \& Laurens, L.M., Microalgae as biodiesel and biomass feedstocks: review and analysis of the biochemistry, energetics and economics. Energy \& Environmental Science, 3, pp. 554-590, 2010. doi: http://dx.doi.org/10.1039/b924978h

[35] Hara, A. \& Radin, N.S., Lipid extraction of tissues with a low toxicity solvent. Analytical Biochemistry, 90(1), pp. 420-426, 1978. doi: http://dx.doi.org/10.1016/0003-2697(78)90046-5

[36] Kabalnov, A. \& Wennerström, H., Macroemulsion stability: the oriented wedge theory revisited. Langmuir, 12(2), pp. 276-292, 1996. doi: http://dx.doi.org/10.1021/la950359e

[37] Rintoul, S., Measuring oil in water. Pollution Engineering, 42(12), 2010.

[38] Nagle, N. \& Lemke, P., Production of methyl-ester fuel from microalgae. Applied Biochemistry and Biotechnology, 24(24-25), pp. 355-361, 1990. doi: http://dx.doi.org/10.1007/bf02920259

[39] Tran, H., Hong, S. \& Lee, C., Evaluation of extraction methods for recovery of fatty acids from Botryococcus braunii LB 572 and Synechocystis sp. PCC 6803. Biotechnology and Bioprocess Engineering, 14(2), pp. 187-192, 2009. doi: http://dx.doi.org/10.1007/s12257-008-0171-8

[40] National Renewable Energy Laboratory, Biodiesel Handling and Use Guide, available at http:// www.nrel.gov/vehiclesandfuels/pdfs/43672.pdf, 2009.

[41] ASTM Standard D6751-10, 2010, Standard specification for biodiesel fuel blend stock (B100) for middle distillate fuels, ASTM International, 2010, West Conshohocken, PA, www.astm. org. doi: http://dx.doi.org/10.1520/d6751-10 
